\title{
Thermal structure of Dome Fuji and east Dronning Maud Land, Antarctica, simulated by a three-dimensional ice-sheet model
}

\author{
Fuyuki SAITO, Ayako ABE-OUCHI \\ Centre for Climate System Research, The University of Tokyo, Komaba 4-6-1, Meguro-ku, Tokyo 153-8904, Japan \\ E-mail: fuyuki@ccsr.u-tokyo.ac.jp
}

\begin{abstract}
Three-dimensional structures of temperature focused on Dome Fuji and east Dronning Maud Land, Antarctica, simulated in a three-dimensional shallow ice model, are reported. With a geothermal heat flux of $54.6 \mathrm{~mW} \mathrm{~m}^{-2}$, as used in several modelling studies of the Antarctic ice sheet, and an enhancement factor of $\mathbf{1 . 3}$, which is smaller than in previous studies, the model result taking into account the glacial cycles is in good agreement with the borehole temperature and surface topography at Dome Fuji. The basal temperature at Dome Fuji must be at or very close to the pressure-melting point. The simulated amplitude of basal temperature through glacial/interglacial cycles is $<1 \mathrm{~K}$.
\end{abstract}

\section{INTRODUCTION}

Understanding the dynamical features and thermal regimes of the Antarctic ice sheet is crucial both for ice-core interpretation and for determining the stability of ice sheets. East Dronning Maud Land is an interesting region in both respects. A deep ice core was drilled recently at Dome Fuji (e.g. Dome-F Deep Coring Group, 1998) and is expected to reach the bedrock in the near future. Both for extracting the ice core and for the interpretation of the core data, it is important to estimate the basal temperature at Dome Fuji (e.g. melting or freezing at present and in the past during glacial cycles). In addition, a substantial thinning of the ice surface has been observed on Shirase Glacier (e.g. Naruse, 1979). Mae (1979) argues that the thinning in this area is caused by basal sliding. The basal thermal feature is an important aspect for dynamics in this region. The main objective of this paper is to understand the temporal/spatial variation of ice-sheet temperature over east Dronning Maud Land, especially at the base of Dome Fuji.

While a number of numerical studies have been made of the Antarctic ice sheet using a three-dimensional ice-sheet model (e.g. Ritz and others, 2001), few of them have focused on east Dronning Maud Land. Furthermore their choices of uncertain parameters are not constrained by the observed surface topography over east Dronning Maud Land and temperature profiles. Pattyn and Decleir (1995) applied a two-dimensional ice-sheet model including longitudinal stress calculation, which focuses on the dynamics of the Shirase drainage basin. However, they had to assume the change in width of the flow band along the flowline, in order to take into account the horizontal convergence/ divergence of the ice flow. Paschke and Lange (2003) applied a three-dimensional ice-sheet model (including computation of normal deviatoric stress gradient) coupled with an ice-shelf model, which focuses on Nivilsen and its drainage area $\left(69-75^{\circ} \mathrm{S}, 9-14^{\circ} \mathrm{E}\right)$, in east Dronning Maud Land. Although they present results on a small-scale grid $(1.25 \times 1.25 \mathrm{~km})$, they only show steady-state results under fixed topography.

In the present study, we report thermal features of Dome Fuji and east Dronning Maud Land simulated by a threedimensional ice-sheet model, whose result is constrained by measurement of the present surface elevation and temperature profile. Several transient experiments forced by glacial/ interglacial environment changes are examined in order to discuss the sensitivity of the temperature distribution to uncertain parameters such as geothermal heat flux.

\section{MODEL DESCRIPTION AND EXPERIMENT DESIGN}

The numerical ice-sheet model and boundary conditions used in the present paper are the same as in Saito (2002). It is a time-dependent, three-dimensional model including thermodynamics. The model inputs are surface mass balance, surface temperature and geothermal heat flux. The model outputs are ice thickness and (three-dimensional) temperature distribution. Glen's flow law with exponent $n=3$ (Paterson, 1994) is assumed for the stress-strain relationship. The shallow-ice approximation is applied (Hutter, 1983). After the approximation, the horizontal velocity vector $\vec{v}_{\mathrm{H}}$ can be calculated using surface elevation $h$ and bedrock topography $b$ :

$$
\begin{aligned}
\vec{v}_{\mathrm{H}}=\vec{v}_{\mathrm{B}}- & 2\left(\rho_{\mathrm{l}} g\right)^{n}\left[\left(\frac{\partial h}{\partial x}\right)^{2}+\left(\frac{\partial h}{\partial y}\right)^{2}\right]^{\frac{n-1}{2}} \\
& \times \int_{b}^{z} \mathrm{~d} z^{\prime} m A(T)\left(h-z^{\prime}\right)^{n} \times \nabla_{\mathrm{H}} h,
\end{aligned}
$$

where $g=9.81 \mathrm{~m} \mathrm{~s}^{-1}$ is the acceleration of gravity, $\rho_{\mathrm{l}}=910 \mathrm{~kg} \mathrm{~m}^{-3}$ is the density of ice, and $\vec{v}_{\mathrm{B}}$ is basal sliding velocity. The rate factor $A(T)$, through which the velocity and temperature fields are coupled, follows Huybrechts (1992) and Paterson (1994). Enhancement factor $m$ in Equation (1), which controls the softness of ice, implicitly reflects the effect of impurity and/or anisotropy of ice. It is used as a tuning parameter to improve the agreement between measured and modelled topography. For instance, Huybrechts and de Wolde (1999) adopt 4.5, and Ritz and others (2001) adopt 3. These parameters are selected to achieve a good fit for overall topography and volume. Basal sliding is assumed to occur only when the basal ice is at the pressure-melting point. In this paper, a Weertman type (Weertman, 1964) is used:

$$
\vec{v}_{\mathrm{B}}=-A_{\mathrm{s}}\left(\rho_{\mathrm{l}} g H \nabla_{\mathrm{H}} h\right)^{3} / Z^{*},
$$

where $Z^{*}$ is the height above buoyancy and the coefficient $A_{\mathrm{s}}$ is set at $1.8 \times 10^{-10} \mathrm{~m}^{7} \mathrm{a}^{-1} \mathrm{~N}^{-3}$ in the present paper. 

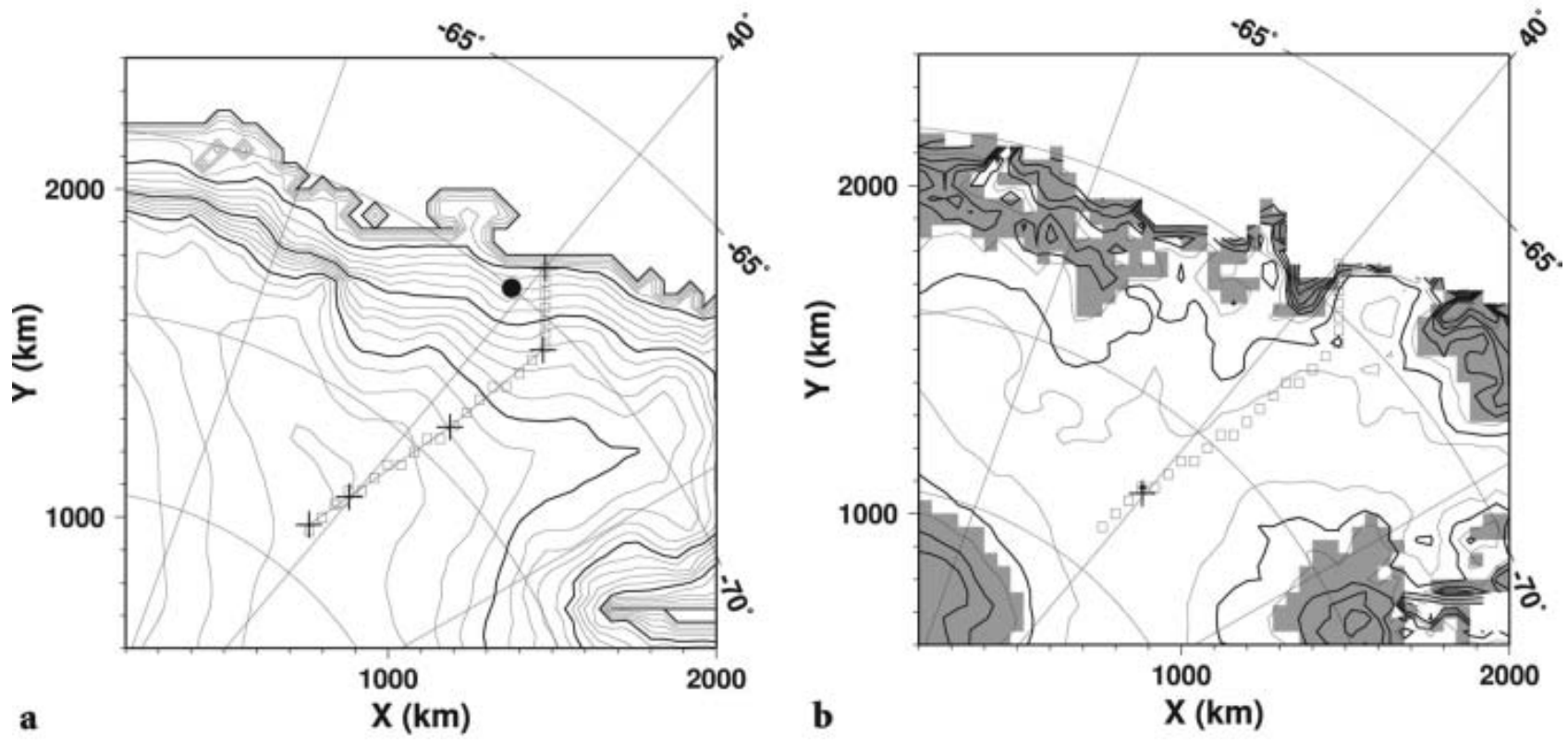

Fig. 1. Simulated present surface topography of the result of experiment C. Only the east Dronning Maud Land area is shown. (a) Simulated surface topography. Contour intervals are $200 \mathrm{~m}$ (thin line) and $1000 \mathrm{~m}$. The cross symbols, from inland to margin, correspond to SSE150, Dome Fuji, MD364, Mizuho and S16, respectively, as presented in Fujita and others (2002). The circle corresponds to the position of Shirase Glacier. (b) Difference between simulated and measured surface topography. Contour intervals are $100 \mathrm{~m}$ (thin line) and $200 \mathrm{~m}$. Dashed lines indicate negative. Shaded region indicates that the difference is $>300 \mathrm{~m}$. The axes give the horizontal distance $(\mathrm{km})$ from the South Pole. The cross symbol corresponds to Dome Fuji. Squares are the sequence of model grids used in Figure 5.

The evolution of ice-thickness distribution is determined by the continuity equation for the local ice thickness with a prescribed surface accumulation function as a boundary condition:

$$
\frac{\partial H}{\partial t}=-\nabla_{\mathrm{H}} \cdot \int_{b}^{h} \mathrm{~d} z \vec{v}_{\mathrm{H}}+M_{\mathrm{s}}
$$

where $H$ is ice thickness and $M_{\mathrm{s}}$ is surface mass balance.

Temperature distribution is calculated from the thermodynamic equation under prescribed surface temperature function and geothermal heat flux as boundary conditions:

$$
\frac{\partial T}{\partial t}=\frac{k_{\mathrm{l}}}{\rho_{\mathrm{l}} C_{\mathrm{p}}} \nabla \cdot \nabla T-(\vec{v} \cdot \nabla) T+\frac{\Phi}{\rho_{\mathrm{l}} C_{\mathrm{p}}}+\frac{L}{\rho_{\mathrm{l}} C_{\mathrm{p}}},
$$

where $k_{\mathrm{l}}=2.1 \mathrm{~W} \mathrm{~m}^{-1} \mathrm{~K}^{-1}$ and $c_{\mathrm{p}}=2009 \mathrm{~J} \mathrm{~kg} \mathrm{~K}^{-1}$ are thermal conductivity and specific heat capacity of ice, respectively, and $\Phi$ and $L$ are strain-heating and phase-change terms, respectively. The prescribed temperature distribution is employed at the surface of the ice. At the bottom of ice, on the other hand, the mixed boundary conditions are employed:

$$
\left\{\begin{array}{cl}
\left.\frac{\partial T}{\partial z}\right|_{\mathrm{b}}=-\frac{\Gamma}{k_{\mathrm{l}}} & \text { if no melting, } \\
T_{\mathrm{b}} & =T_{\mathrm{pm}}
\end{array}\right.
$$

The geothermal heat flux $\Gamma$ is taken as constant. Changes in the glacier bed elevation are calculated by an equation expressing local isostatic rebound:

$$
\frac{\partial b}{\partial t}=\frac{1}{\tau_{\mathrm{b}}}\left(b-e+\frac{\rho_{\mathrm{l}}}{\rho_{\mathrm{M}}} H\right),
$$

where $\rho_{M}=3300 \mathrm{~kg} \mathrm{~m}^{-3}$ is the density of mantle, and $e$ is the prescribed equilibrium elevation of bedrock with no ice loading, which is obtained by the simple assumption that the present condition is in equilibrium. The time constant for isostatic rebound, $\tau_{\mathrm{b}}$, is set at 3000 years in the present paper (Turcotte and Schubert, 1982).

Surface mass balance is calculated only by accumulation rate. It is expressed as the product of a reference value and a temperature-dependent factor. The temperature dependence of accumulation rate follows Huybrechts and Oerlemans (1990). The present reference accumulation follows the data compiled by Huybrechts and others (2000) with modification at Dome Fuji to $2.75 \mathrm{~cm} \mathrm{a}^{-1}$, according to Satow and others (1999).

Surface annual temperature $T_{\mathrm{S}}$ is parameterized as a function of latitude and surface elevation (Fortuin and Oerlemans, 1990):

$$
T_{\mathrm{s}}=B_{1} \mathrm{~s}+B_{2} \phi+B_{3}+\Delta T_{\mathrm{s}},
$$

where $s$ is surface elevation and $\phi$ is latitude (in ${ }^{\circ} \mathrm{S}$ ). The offset $B_{3}$ is chosen to fit the present condition. Background temperature $\left(\Delta T_{\mathrm{s}}\right.$ in Equation (7)) and sea-level shift over $220 \mathrm{kyr}$ follow the configuration of Huybrechts (1998). The coefficients $B_{n}$ in Equation (7) follow those presented in Pattyn and Decleir (1995), which are based on the observation over Shirase drainage basin by Satow and Kikuchi (1995).

$$
\begin{aligned}
& B_{1}=-0.01085, B_{2}=-0.222244, B_{3}=6.440234 \\
& (h<2000 \mathrm{~m}), \\
& B_{1}=-0.011068, B_{2}=-0.820738, B_{3}=48.623326 \\
& \quad(h \geq 2000 \mathrm{~m}) .
\end{aligned}
$$

The units of coefficients $B_{1}, B_{2}$ and $B_{3}$ are ${ }^{\circ} \mathrm{C} \mathrm{m}^{-1}$, ${ }^{\circ} \mathrm{C}$ degree $^{-1}$ and ${ }^{\circ} \mathrm{C}$, respectively. Given the observed surface elevation and location of Dome Fuji, the calculated surface temperature differs only by $1^{\circ} \mathrm{C}$ and shows good agreement with the observed value.

There are large uncertainties in the choice of ice 
enhancement factor and geothermal heat flux. In the present paper, three experiments, C, E and G, are presented. The control experiment $\mathrm{C}$ applies enhancement factor 1.3 and geothermal heat flux $54.6 \mathrm{~mW} \mathrm{~m}^{-2}$. Experiment $\mathrm{E}$ applies a different enhancement factor, $m=3$, and the same geothermal heat flux as the control. Experiment $\mathrm{G}$ applies enhancement factor 3 and geothermal heat flux $46 \mathrm{~mW} \mathrm{~m}^{-2}$. The higher geothermal heat flux of experiments $\mathrm{C}$ and $\mathrm{E}$ is used in several modelling studies of the Antarctic ice sheet (Pattyn and Decleir, 1995; Huybrechts and de Wolde, 1999; Ritz and others, 2001), following Sclater and others (1980). Enhancement factor 3 is used by Ritz and others (2001), who focus on East Antarctica.

All of them are transient experiments, forced by glacial/interglacial change in background temperature and sea level through $220 \mathrm{kyr}$. Forcings follow the configuration of Huybrechts (1998, 2002): Temperature forcing is based on Vostok surface temperature change (Petit and others, 1999). Sea-level forcing is based on the SPECMAP stack (Imbrie and others, 1984). The initial condition itself is the final state of the transient experiment beginning from the corresponding steady-state result (as in Ritz and others, 2001). All experiments are simulated for $660 \mathrm{kyr}$ in total.

The boundary conditions and parameters other than geothermal heat flux and parameterization of surface temperature are fixed in all three experiments. The model domain spans $5600 \times 5600 \mathrm{~km}$, centered at the South Pole. The horizontal resolution is $40 \mathrm{~km}$. The bedrock topography is based on the BEDMAP database (Lythe and others, 2000). Different time-steps are used for solving dynamic evolution ( $\Delta t=4.0$ years) and thermodynamic evolution $(\Delta t=20.0$ years $)$.

\section{RESULTS AND DISCUSSION}

Figure 1 shows the simulated surface topography over east Dronning Maud Land obtained by the control experiment $\mathrm{C}$ at final state (present). Elevation distribution is well simulated over a large area within $+100 \mathrm{~m}$. The simulated elevation at Dome Fuji is $3802 \mathrm{~m}$, which is very close to the present observed value $(3810 \mathrm{~m})$. However, the elevation of other interior parts of East Antarctica such as Vostok and Dome $\mathrm{C}$ is overestimated by around $100 \mathrm{~m}$ (not shown). This discrepancy may be due to an incorrect uniform enhancement factor or to uncertainties in the bedrock topography data.

In the sensitivity experiment, $\mathrm{E}$, using a larger enhancement factor 3, the elevation distribution is well simulated within $\pm 100 \mathrm{~m}$ over a large area of east Dronning Maud Land. The interior part of East Antarctica, especially around Vostok, is also well simulated, within around $10 \mathrm{~m}$ difference (not shown). However, the simulated elevation at Dome Fuji is $3660 \mathrm{~m}$, which is $150 \mathrm{~m}$ less than observed. This paper focuses especially on the temperature profile at Dome Fuji. Since simulated thickness (elevation) affects not only the surface temperature, but also the pressure-melting point at the base, the authors regard experiment $C$ as the best simulation.

The simulated surface topography also shows discrepancies within the coastal region, where elevation is overestimated by $>300 \mathrm{~m}$. This can be attributed to the coarse grid resolution of the present paper. Saito (2002) presents a numerical experiment with a $20 \mathrm{~km}$ grid resolution model, and shows that the overestimation of the coastal region is

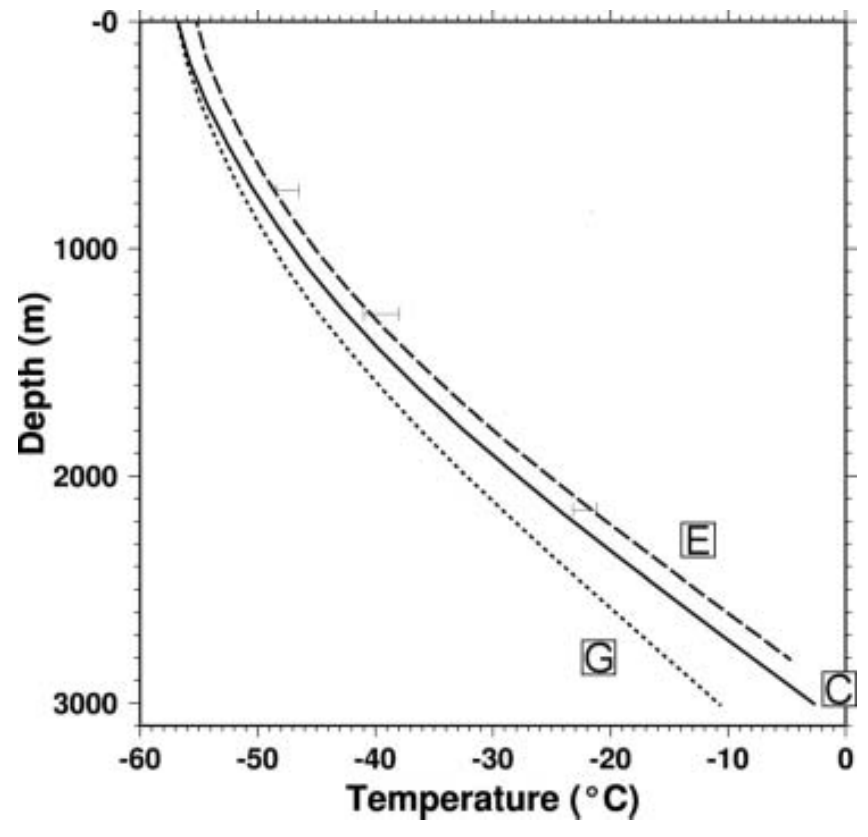

Fig. 2. Vertical profile of simulated present temperature at Dome Fuji grid. Borehole temperature measurement (presented in Hondoh and others, 2002) at Dome Fuji is also shown by three error bars.

reduced by around $100 \mathrm{~m}$ while the elevation of the interior is hardly affected. Thus the result of the present paper is considered to be less affected by a refinement to $20 \mathrm{~km}$ resolution, for example, especially in the interior part.

Figure 2 shows vertical profiles of temperature at Dome Fuji obtained by the three experiments, together with borehole temperature measurements (error bar) presented by Hondoh and others (2002). The result shows that the vertical advection dominates the temperature profile from the surface to $1000 \mathrm{~m}$ depth, and that the geothermal heat flux dominates it from the depth to the bottom. The simulated bottom temperature obtained by the control experiment $\mathrm{C}$ is $-2.6^{\circ} \mathrm{C}$, which is at the pressure-melting point. Note that a pressure-melting point at the base of an ice sheet becomes $<0^{\circ} \mathrm{C}$ due to the overburden pressure of $3 \mathrm{~km}$ thick ice. Comparison between the borehole temperature gradient and the simulated gradient suggests that the geothermal heat flux used in experiment $C\left(54.6 \mathrm{~mW} \mathrm{~m}^{-2}\right)$ is slightly overestimated. However, the result of experiment $C$ shows good agreement with the measured temperature. On the other hand, the result obtained by experiment $G$ (with geothermal heat flux $46 \mathrm{~mW} \mathrm{~m}^{-2}$ ) is not as good, in spite of well-simulated elevation at Dome Fuji.

Since the present ice-sheet model lacks the effect of longitudinal stress gradient, a 'hot spot' below the divide (Dahl-Jensen, 1989) cannot be expressed. The difference in temperature between a hot spot and the surrounding area is expected to be of the order of $1^{\circ} \mathrm{C}$ (Saito and others, 2003). Thus the bottom of Dome Fuji may well be at the pressuremelting point.

Figure 3 shows the distribution of the pressure-melting area at the base over east Dronning Maud Land obtained by experiments $C$ and $G$. The result of experiment $C$ shows that the region where bedrock is low, including Shirase Glacier, is melting. Although Shirase Glacier cannot be well reproduced by a shallow-ice model, relatively higher velocity occurs there. This leads to large strain heating, 


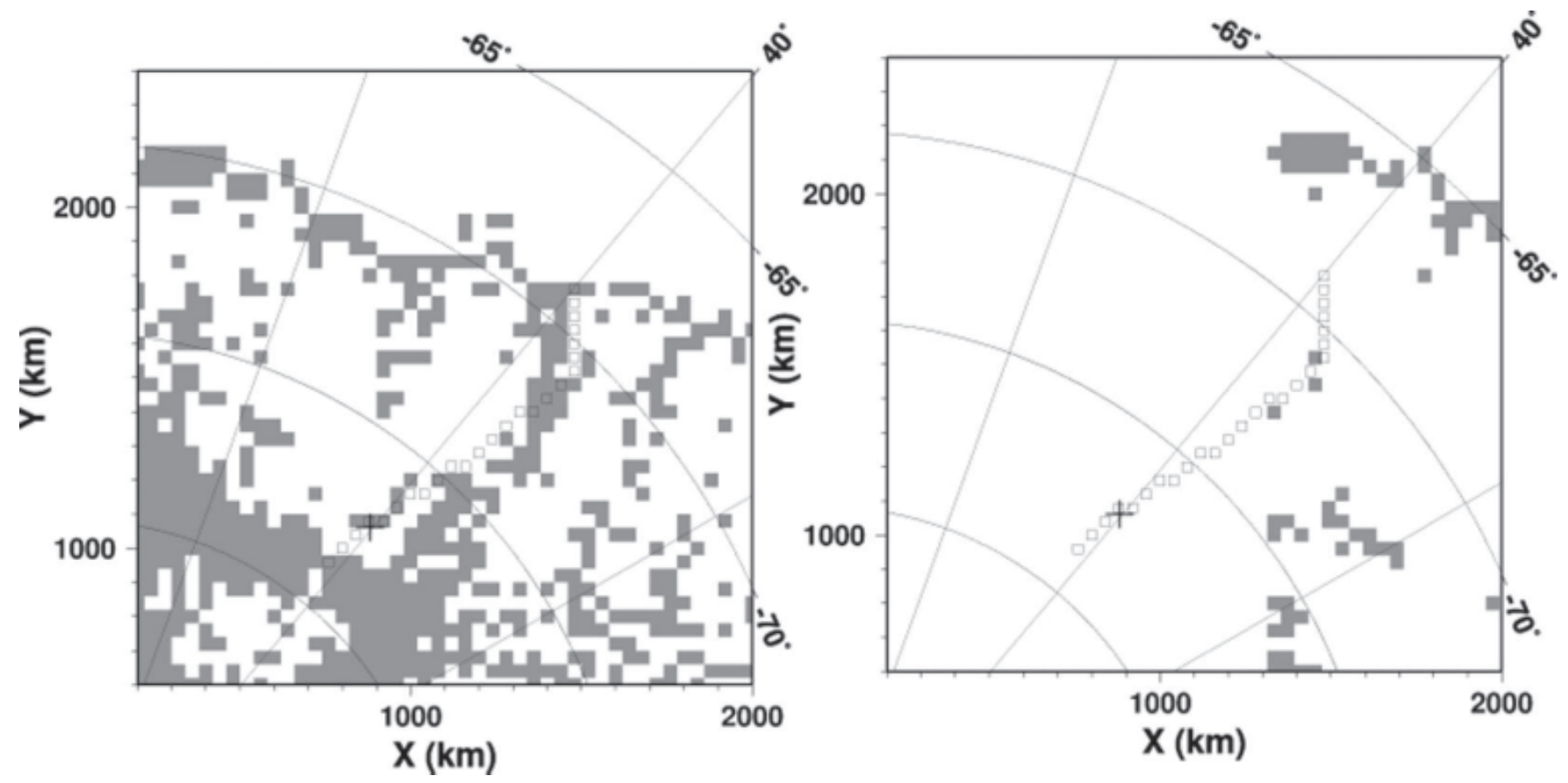

Fig. 3. Simulated present basal-melting area from the results of experiments $C$ and G. Shaded area indicates that the base is at pressuremelting point. Only the east Dronning Maud Land area is shown. The axes give the horizontal distance $(\mathrm{km})$ from the South Pole. Squares are the sequence of model grids used in cross-section figures. The cross symbol corresponds to Dome Fuji.

which results in basal melting. In addition, the result is consistent with Paschke and Lange (2003) around their study area $\left(70^{\circ} \mathrm{S}, 11^{\circ} \mathrm{E}\right)$, which shows basal melting conditions. The result of experiment $G$ shows that the basal melting area, especially inland, is much reduced according to lower geothermal heat flux, but that the base of Shirase Glacier is melting even if lower geothermal heat flux is applied.

In Figure 4 the change in simulated surface (upper) and basal (lower) temperature at Dome Fuji throughout the glacial/interglacial cycles is shown. Only the result of experiment $\mathrm{C}$ is shown for the surface temperature. The variations of simulated surface temperature obtained by experiments $E$ and $G$ are the same, but with different offset due to different elevation. In the control experiment $\mathrm{C}$, the ice base at Dome Fuji keeps melting throughout the experiment period. In the other two experiments, the amplitudes of basal temperature are at most about $1 \mathrm{~K}$. The results show that the amplitude of basal temperature throughout the ice-age cycles is not strongly dependent on the uncertain parameters. Basal temperature at present is at the lower phase through $100 \mathrm{kyr}$. The phase of basal temperature is opposite to that of surface temperature variation. The basal temperature at present is at the lower phase during a glacial/interglacial cycle, due to the slow response time of thermodynamics.

Figure 5 is the present modelled temperature distribution. The vertical cross-section along the line indicated by the sequence of squares in Figure 1 is shown. The sampling line roughly corresponds to the traverse route shown in Fujita and others (2002), which passes Dome Fuji and Mizuho and avoids the main flow of Shirase Glacier. The results show a qualitatively similar distribution of temperature. Isolines shift almost according to bedrock undulation. The lower layer of about $1000 \mathrm{~m}$ a.s.l., temperature change in the vertical direction is almost linear due to diffusion. Horizontal advection of cold ice becomes larger from $600 \mathrm{~km}$ distance.
The result of experiment $C$ shows that basal melting may occur in the region where the surface elevation is $<2800 \mathrm{~m}$, which is consistent with the measurement by Mae (1979). On the other hand, with low geothermal heat flux, few gridpoints show pressure-melting. In this lower region, the basal frictional heating significantly affects the basal thermal regime. There are also several gridpoints showing pressuremelting conditions where the surface elevation is $>3000 \mathrm{~m}$. Compared to the lower region, the vertical temperature gradient at the base is smaller in this higher region, which means that the basal frictional heating has a relatively minor effect at the base. Instead, geothermal heat flux or larger ice loading is thought to control the basal melting in this region through heat conduction.

Several previous studies have applied different choices for uncertain parameters. Ritz and others (2001) focus mainly on Vostok but also present simulated elevation at Dome Fuji. They apply enhancement factor 3 and geothermal heat flux $55 \mathrm{~mW} \mathrm{~m}^{-2}$, which are almost the same settings as for experiment $E$ in the present paper. The surface elevation at Dome Fuji simulated by Ritz and others (2001), however, is $60 \mathrm{~m}$ lower than observed. This is because their present-day accumulation value at Dome Fuji is $3.9 \mathrm{~cm} \mathrm{a}^{-1}$, which is larger than the value used in the present study $\left(2.75 \mathrm{~cm} \mathrm{a}^{-1}\right)$. Huybrechts and de Wolde (1999) and Huybrechts (2002) use a similar geothermal heat flux $\left(\sim 56 \mathrm{~mW} \mathrm{~m}^{-2}\right)$ and also a larger enhancement factor (4.5) than the present paper. The West Antarctic ice sheet and the area around Vostok is well represented by their choice, while the surface elevation around Dome Fuji is underestimated by about $200 \mathrm{~m}$ due to the large enhancement factor. Pattyn and Decleir (1995) apply a two-dimensional ice-sheet model including longitudinal stress calculation over the Shirase drainage basin. Almost the same geothermal heat flux is used as in the present study, and the simulated surface elevation is close to the measured value. This is because a small enhancement 

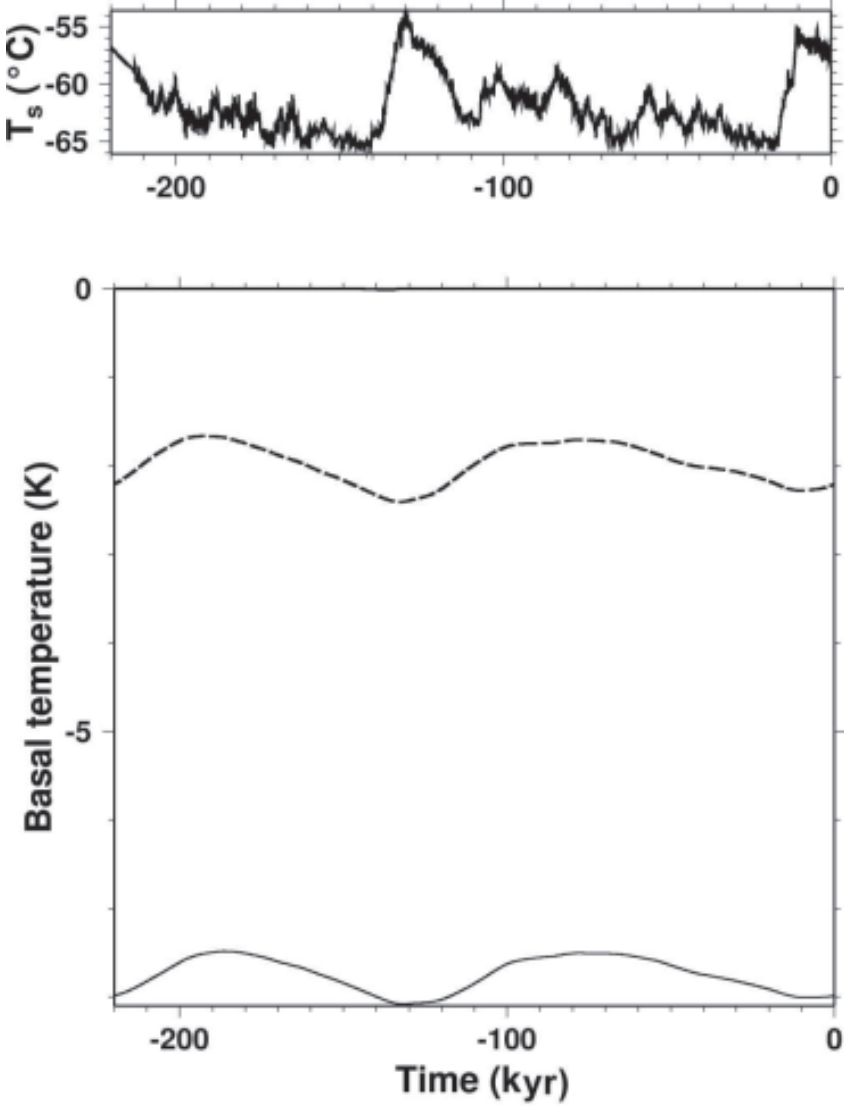

Fig. 4. Upper: time series of simulated surface temperature at Dome Fuji grid obtained by experiment C. Lower: time series of simulated basal temperature, relative to pressure-melting point, at Dome Fuji grid obtained by experiments $\mathrm{C}, \mathrm{E}$ and $\mathrm{G}$. In experiment $\mathrm{C}$, basal temperature at Dome Fuji reaches pressure-melting point through the simulated period. Horizontal axis is the lapsed time in kyr, and $0 \mathrm{kyr}$ corresponds to the present.

factor of 0.6 is adopted to obtain a close fit to the measured value. However, if we select a small enhancement factor as above in order to obtain a good representation of the surface elevation at Dome Fuji, the other region will be significantly overestimated. We believe that one of the reasons for this is uncertainty in the bedrock topography data on east Dronning Maud Land. Since the ice velocity depends on the ice thickness in the fourth power under the shallow-ice approximation, a small error in bedrock topography greatly affects the modelled results. Saito (2002) performed a sensitivity study on bedrock topography, using Drewry's (1983) bedrock topography map and Lythe and others (2000), and showed that the simulated thickness and position of Dome Fuji are affected by the difference in bedrock boundary conditions. Investigation for bedrock topography on east Dronning Maud Land is also needed.

\section{CONCLUSION AND PROSPECT}

In the present study, the temperature distribution over east Dronning Maud Land simulated by a three-dimensional shallow ice model is reported. If the geothermal heat flux is $54.6 \mathrm{~mW} \mathrm{~m}^{-2}$ as applied in several modelling studies of the Antarctic ice sheet (Budd and others, 1998; Huybrechts and de Wolde, 1999; Payne, 1999; Ritz and others, 2001), the bottom of Dome Fuji may be at pressure melting, and the
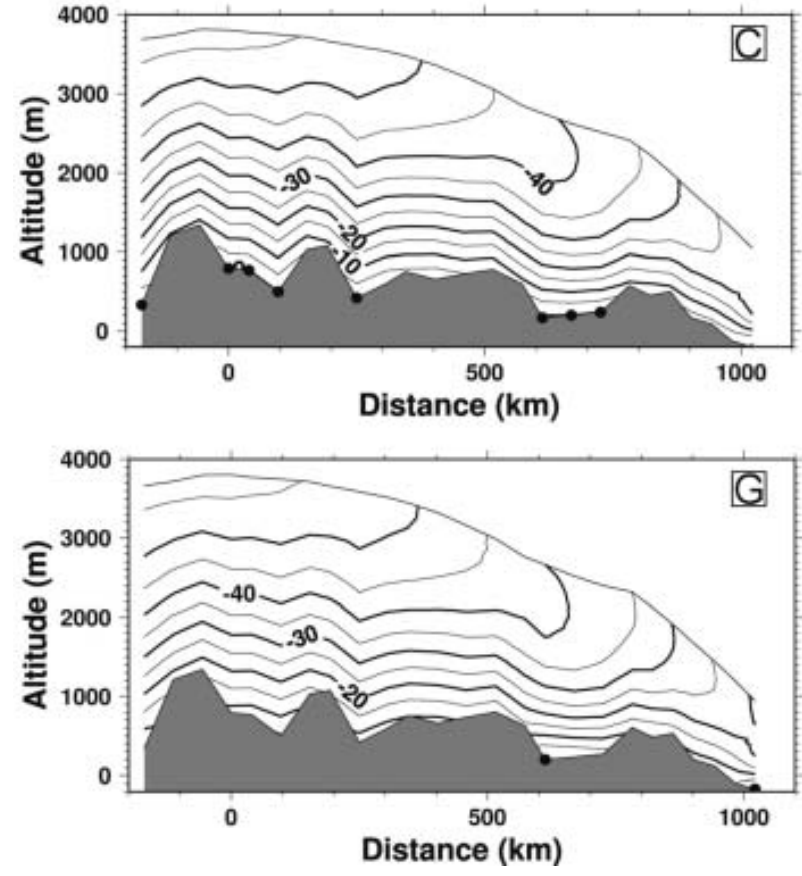

Fig. 5. Cross-section of present temperature distribution obtained by experiments $\mathrm{C}$ and $\mathrm{G}$. Contour intervals are $5 \mathrm{~K}$ (thin lines) and $10 \mathrm{~K}$ (thick lines). Samples are along the squares in Figure 1. Circles on the base indicate that the corresponding grid is at pressure-melting point at the base. Horizontal axis is the distance from the Dome Fuji gridpoint.

vertical profile of temperature at Dome Fuji is close to the borehole temperature. This result is consistent with Hondoh and others (2002), and closer to the pressure-melting point than the result by Pattyn and Decleir (1995). Sensitivity studies are examined for both the enhancement factor and the geothermal heat flux. In addition, the vertical profile of temperature at Dome Fuji is consistent with the borehole temperature. The amplitude of basal temperature through glacial/interglacial cycles is no more than $1 \mathrm{~K}$ and is not affected by boundary conditions. Several studies are planned for the future. Extensive fieldwork by radar-echo sounding has been performed on east Dronning Maud Land (Fujita and others, 1999, 2002; Matsuoka and others, 2002). Comparison between observed and modelled features is expected to help understanding of the internal structure over east Dronning Maud Land. The present study is based on the shallow-ice approximation, which breaks down near ice divides. Nesting of a higher-order mechanics model, developed in Saito and others (2003), into a shallow-ice model is being constructed. More detailed discussion on vertical thermal structure at Dome Fuji is expected to result from the model.

\section{ACKNOWLEDGEMENTS}

The authors thank B. Paschke and an anonymous referee for their valuable comments on the manuscript.

\section{REFERENCES}

Budd, W. F., B. Coutts and R.C. Warner. 1998. Modelling the Antarctic and Northern Hemisphere ice-sheet changes with global climate through the glacial cycle. Ann. Glaciol., 27, 153-160. 
Dahl-Jensen, D. 1989. Steady thermomechanical flow along twodimensional flow lines in large grounded ice sheets. J. Geophys. Res., 94(B8), 10,355-10,362.

Dome-F Deep Coring Group. 1998. Deep ice-core drilling at Dome Fuji and glaciological studies in east Dronning Maud Land, Antarctica. Ann. Glaciol., 27, 333-337.

Drewry, D. J. 1983. Antarctica: glaciological and geophysical folio. Cambridge, University of Cambridge. Scott Polar Research Institute.

Fortuin, J.P. F. and J. Oerlemans. 1990. Parameterization of the annual surface temperature and mass balance of Antarctica. Ann. Glaciol., 14, 78-84.

Fujita, S. and 6 others. 1999. Nature of radio-echo layering in the Antarctic ice sheet detected by a two-frequency experiment. J. Geophys. Res., 104(B6), 13,013-13,024.

Fujita, S., H. Maeno, T. Furukawa and K. Matsuoka. 2002. Scattering of VHF radio waves from within the top $700 \mathrm{~m}$ of the Antarctic ice sheet and its relation to the depositional environment: a case-study along the Syowa-Mizuho-Dome Fuji traverse. Ann. Glaciol., 34, 157-164.

Hondoh, T., H. Shoji, O. Watanabe, A.N. Salamatin and V. Ya. Lipenkov. 2002. Depth-age and temperature prediction at Dome Fuji station, East Antarctica. Ann. Glaciol., 35, 384-390.

Hutter, K. 1983. Theoretical glaciology; material science of ice and the mechanics of glaciers and ice sheets. Dordrecht, etc., D. Reidel Publishing Co.; Tokyo, Terra Scientific Publishing Co.

Huybrechts, P. 1992. The Antarctic ice sheet and environmental change: a three-dimensional modelling study. Ber. Polarforsch. 99

Huybrechts, P. 1998. Report of the third EISMINT workshop on model intercomparison. Strasbourg, European Science Foundation.

Huybrechts, P. 2002. Sea-level changes at the LGM from icedynamic reconstructions of the Greenland and Antarctic ice sheets during the glacial cycles. Quat. Sci. Rev., 21(1-3), 203-231.

Huybrechts, P. and J. de Wolde. 1999. The dynamic response of the Greenland and Antarctic ice sheets to multiple-century climatic warming. J. Climate, 12(8), 2169-2188.

Huybrechts, P. and J. Oerlemans. 1990. Response of the Antarctic ice sheet to future greenhouse warming. Climate Dyn., 5(2), 93-102.

Huybrechts, P., D. Steinhage, F. Wilhelms and J. Bamber. 2000. Balance velocities and measured properties of the Antarctic ice sheet from a new compilation of gridded data for modelling. Ann. Glaciol., 30, 52-60.

Imbrie, J. and 8 others. 1984. The orbital theory of Pleistocene climate: support from a revised chronology of the marine $\delta^{18} \mathrm{O}$ record. In Berger, A., J. Imbrie, J. Hays, G. Kukla and B. Saltzman, eds. Milankovitch and climate: understanding the response to astronomical forcing. Part 1. Dordrecht, etc., D. Reidel Publishing Co., 269-305.
Lythe, M. B., D. G. Vaughan and BEDMAP consortium. 2000. BEDMAP - bed topography of the Antarctic. (Scale $1: 10,000,000$.) British Antarctic Survey. (BAS (Misc) 9, http:// www.antarctica.ac.uk/aedc/bedmap/.)

Mae, S. 1979. The basal sliding of a thinning ice sheet, Mizuho Plateau, East Antarctica. J. Glaciol., 24(90), 53-61.

Matsuoka, K., H. Maeno, S. Uratsuka, S. Fujita, T. Furukawa and O. Watanabe. 2002. A ground-based, multi-frequency icepenetrating radar system. Ann. Glaciol., 34, 171-176.

Naruse, R. 1979. Thinning of the ice sheet in Mizuho Plateau, East Antarctica. J. Glaciol., 24(90), 45-52.

Paschke, B. and M. A. Lange. 2003. Dynamics and mass balance of the ice sheet/ice shelf regime at Nivlisen, Antarctica, as derived from a coupled three-dimensional numerical flow model. Ann. Glaciol., 37, 159-165.

Paterson, W.S.B. 1994. The physics of glaciers. Third edition. Oxford, etc., Elsevier.

Pattyn, F. and H. Decleir. 1995. Numerical simulation of Shirase Glacier, East Queen Maud Land, Antarctica. Proc. NIPR Symp. Polar Meteorol. Glaciol., 9, 87-109.

Payne, A. J. 1999. A thermomechanical model of ice flow in West Antarctica. Climate Dyn., 15(2), 115-125.

Petit, J.-R. and 18 others. 1999. Climate and atmospheric history of the past 420,000 years from the Vostok ice core, Antarctica. Nature, 399(6735), 429-436.

Ritz, C., V. Rommelaere and C. Dumas. 2001. Modeling the evolution of Antarctic ice sheet over the last 420,000 years: implications for the altitude changes in the Vostok region. J. Geophys. Res., 106(D23), 31,943-31,964.

Saito, F. 2002. Development of a three dimensional ice sheet model for numerical studies of Antarctic and Greenland ice sheet. Tokyo, University of Tokyo. Center for Climate System Research. (CCSR Report 15.)

Saito, F., A. Abe-Ouchi and H. Blatter. 2003. Effects of firstorder stress gradients in an ice sheet evaluated by a threedimensional thermomechanical coupled model. Ann. Glaciol., 37, 166-172.

Satow, K. and T. Kikuchi. 1995. The $10 \mathrm{~m}$ snow temperature in the ice sheet. In Higashi, A., ed. Antarctica, east Queen Maud Land, Enderby Land glaciological folio. Tokyo, National Institute of Polar Research, Map.

Satow, K., O. Watanabe, H. Shoji and H. Motoyama. 1999. The relationship among accumulation rate, stable isotope ratio and surface temperature on the plateau of east Dronning Maud Land, Antarctica. Polar Meteorol. Glaciol., 13, 43-52.

Sclater, J. G., C. Jaupart and D. Galson. 1980. The heat flow through oceanic and continental crust and the heat loss of the Earth. Rev. Geophys. Space Phys., 18(1), 269-311.

Turcotte, D. L. and G. Schubert. 1982. Geodynamics: applications of continuum physics to geological problems. New York, John Wiley and Sons.

Weertman, J. 1964. The theory of glacier sliding. J. Glaciol., 5(39), 287-303. 